\title{
On Development Strategies for Improving the Management Level of Chinese Enterprises in Africa: the case of Chinese enterprises in Kenyan
}

\author{
Jiaxiu Wang ${ }^{1}$ \\ ${ }^{1}$ Zhejiang Normal University, China \\ Correspondence: Jiaxiu Wang, Zhejiang Normal University, China. E-mail: wangjiaxiu@zjnu.edu.cn
}

Received: September 9, 2021

Accepted: September 23, $2021 \quad$ Online Published: October 13, 2021

doi:10.5539/jpl.v14n4p136

URL: https://doi.org/10.5539/jpl.v14n4p136

\begin{abstract}
China has become Africa's largest trading partner. The level of economic and trade cooperation between China and Kenya have been continuously improved within the framework of the China-Africa Community of Shared Future and the "Belt and Road" cooperation. Nowadays, the cooperation between China and Kenya is standing at a new starting point and facing new development opportunities. Chinese enterprises in Kenya have developed rapidly in terms of number and scale in recent years. And the businesses involve a wide range of fields, ranging from agricultural and sideline products and food industry to precision parts processing and manufacturing, which have created a considerable number of jobs for the local area and increased the overall labor income. However, there are still many outstanding problems in specific cooperation practices, such as the lack of attention on corporate management and corporate culture. Based on literature analysis, this article uses Chinese enterprises in Kenya as an example to illustrate the development status of Chinese companies in Africa, study the problems that exist in the development of Chinese companies in Kenya and propose solutions to the corresponding problems. The further development of Chinese enterprises in Africa will promote the better realization of the China-Africa community with a shared future and the development of the "Belt and Road" to achieve a win-win situation.
\end{abstract}

Keywords: China-Africa community with a shared future, one belt one road development strategy, management level of enterprises, Chinese enterprises in Kenyan

\section{Introduction}

According to the Statistical Bulletin of China's Foreign Direct Investment in 2018, China's investment in Africa in 2018 was 5.39 billion U.S. dollars, a year-on-year increase of $31.5 \%$. And Kenya was one of the main destinations. At the end of 2018, China's investment stock in Africa was 46.1 billion U.S. dollars, and Kenya is one of the main distribution countries of the investment stock. Kenya is one of the countries with a good economic foundation in sub-Saharan Africa and the most developed country in East and Central Africa (M. Chege,2008). Kenya also ranks among the top in terms of the number of overseas Chinese companies. The year 2021 marks the 58th anniversary of the establishment of diplomatic relations between China and Kenya. China has become Kenya's largest trading partner, largest source of investment, and largest project contractor, in that case, China has become an important force in helping Kenya's economic development. However, problems such as corporate management and corporate culture issues have gradually been exposed in the development process of Chinese companies in Kenya. These problems have slowed down the development of the company to a certain extent. Therefore, studying and overcoming these problems can further promote the overall development of Chinese companies in Kenya. It can also provide a good example for the development of Chinese enterprises in other countries of the African continent, and then promote the cooperation between China and African countries. China's strengthening of cooperation with African countries is based in the interests of China and African countries. The development results of the China-Africa Community with a Shared Future and the Belt and Road Initiative will also benefit the people of both sides.

\section{Method}

This article adopts the literature analysis method. Quantitative analysis is carried out on the data published mainly from official sources and part of the data collected from the literature collation. This paper conducts a qualitative analysis of a large amount of literature and the final results are presented in text form. Through a large number of 
literatures, the author found that while the prospects for the development of China-Africa economic and trade cooperation are prosperous, there are also many development problems, mainly focusing on the development of Chinese companies in Africa. In order to make the problem more concentrated and visualized, this article uses specific examples of the development of Chinese enterprises in Kenya, hoping to adopt a small approach to analyze the overall development of Chinese enterprises in Africa. Through a large number of thematic literature reviews on the cooperation between China and Kenya, it is found that most of the literature focuses on economic and trade cooperation, natural resources cooperation, cultural exchanges, assistance, etc. And part of the analysis of the development of Chinese enterprises in Kenya stays in the first ten years of the 21 st century. In that case, this article is dedicated to analyzing the latest literature and trying to grasp the current status of the development of Chinese enterprises in Kenya. Because the COVID-19 has swept the world and caused varying degrees of harm to the productivity and development of companies around the world nowadays. At this moment, the problems of enterprise development are exposed increasingly obvious, which is not conducive to the resumption of work and production. Discussing the development of Chinese enterprises in Kenya not only plays a key role in the survival of enterprises, but also accelerates the recovery of Kenya's own economic development. When facing new public health challenges, the people of China and African countries should not be afraid or retreat. Instead, China and Kenya should turn crises into opportunities and open up new directions and new paths in the cooperative fight against the epidemic. At the same time, China and Africa are also expanding the scope of economic development. The overall coordination and interaction will provide a new direction and platform to inject vitality for the further development of the China-Africa Community of a Shared Future.

\section{The Development Status of Chinese Enterprises in Kenya}

With the rapid development of industry, China imports a large amount of oil and minerals from Africa. ChinaAfrica trade volume was less than 5 billion U.S. dollars in the mid-1990s and reached approximately 206.832 billion U.S. dollars in 2019. The "Going Global" policy of reform and opening up encourages Chinese companies to become multinational companies. China's newly signed contracts in Africa amounted to 48.64 billion U.S. dollars and completed a turnover of 37.5 billion U.S. dollars. In recent years, China's investment in Africa has become diversified. Although oil and mining are still the key areas of China's investment in Africa, the foreign direct investment of Chinese companies has gradually extended to other areas, ranging from food processing to manufacturing. Chinese companies have also made major investments in infrastructure in Africa, targeting key areas such as telecommunications, transportation, construction, power plants, waste treatment and renovation. Considering the scale of Africa's infrastructure construction deficit, these investments have made a vital contribution to Africa's sustainable development.

The development status of Chinese enterprises in Kenya presents the following characteristics. One is the rapid development and huge number of enterprises. The data shows that nine new Chinese companies started operations in Kenya in 2000, 18 new registered companies from 2001 to 2002, 11 new companies in 2003, 12 new companies in 2004, 13 new companies in 2005, and 9 new ones were added in 2006. From the year 2000 to 2006, there were 72 Chinese companies established in Kenya with a total of 4,940 employees, of which 326 were Chinese. By 2018, there are nearly 400 Chinese-funded enterprises in Kenya, covering many fields such as agricultural processing, infrastructure, energy development, logistics and commerce. Chinese investment in various enterprises in Kenya has developed rapidly, and there are also differences in development speed. The capital cost of China Yellow Brand Grain Processing Co., Ltd. in 2000 was 924,000 U.S. dollars, while the capital cost of Chinese supermarket chains in 2003 was 11,154,000 U.S. dollars. The "2018-2019 Social Responsibility Report of Chinese Enterprises in Kenya" released by the Kenya-China Economic and Trade Association shows that in 2018, Chinese enterprises in the association created more than 50,000 jobs for local people, with a staff localization rate of $96 \%$, and invested in social responsibility more than 75 million U.S. dollars.

Second, Chinese enterprises in Kenya involve a wide range of fields. The products produced and exported by the company include corn and wheat processing, mushroom cultivation, sausage production and ostrich breeding, solar panel manufacturing and bicycle manufacturing. Except for coffee production companies, the other companies have expanded their business to manufacturing and service industries. For example, in 2016, the Kenyan Ministry of Industry and China signed a new steel plant project, which will build Kenya's first composite steel plant, alleviating the shortage of steel products in Kenya, and greatly promoting the development of Kenya's construction industry.

Kenya has a great demand for steel, but the steel mainly relies on imports. The government's steel procurement expenses this year have increased by $16.7 \%$ compared with the same period last year because of the domestic construction of civil engineering. In that case, it is urgent to build Kenya's own steel plant. It is predicted that domestic steel demand will reach 2.5 million tons in 2020, and the demand will double in 2030. In addition, China's 
business in Kenya also involves the construction and upgrading of important infrastructure, such as roads, real estate, railways, ports, and airports. For Kenya, the actual significance far exceeds the level of enterprise's development and is closer to developing partnerships. At the same time, this also constitutes the foundation for building a much-needed and long-overdue sustainable economy, which will help Kenya's overall economic growth in the long run.

Third, the labor conditions of enterprises are relatively stable. The continuous influx of new enterprises and the continuous expansion of the original enterprise scale have created a considerable number of jobs in the local area, thereby increasing the overall labor income of Kenya, and generally winning the warm welcome and wide support of the local government and people (Xu Hao,2019). For those who are employed as production workers in the manufacturing industry, the wages and labor conditions of Chinese companies in Kenya are relatively fair. The data shows that the average monthly salary of such workers in large companies with more than 100 employees is 116 U.S. dollars, which is equivalent to the national average in Kenya. Medium-sized companies employing between 20 and 99 employees also earn 116 U.S. dollars, while workers in medium-sized companies with fewer than 20 employees earn 93 U.S. dollars per month. And the enterprises pay attention to the cultivation of local labor. For example, in 2010, AVIC International Complete Set Company signed a vocational education project contract with the Ministry of Higher Education of Kenya. And in July 2015, AVIC signed an agreement with the Ministry of Higher Education of Kenya to upgrade the training equipment of 39 schools.

\section{Problems in the Development of Chinese Enterprises in Kenya}

As early as September 2013, the Kenyan government planned to establish Africa's first Chinese Yuan Clearing House and incorporate the Chinese Yuan into its foreign exchange reserve currency system to comply with the rapid development of trade between China and Africa. The establishment of a Chinese Yuan Clearing House will reduce dependence on the US Dollar as an intermediate currency and transaction costs to improve efficiency. At the same time, for China, this will also help realize the internationalization of the Chinese Yuan. It can be seen that China and Kenya have a bright future for cooperation from the Kenyan government's strong desire to establish an offshore Chinese Yuan Clearing Center in Africa. Kenya's friendly foreign investment policies and the rapid development of the market economy have resulted in increasingly fierce competition among enterprises. Therefore, enterprise's management and cultivating enterprise's human resources have become important factors for enterprise's development. In that case, it is necessary to increase human resource reserves and improve human quality. The following will discuss the issues related to enterprise's management and human resources in the development process of Chinese enterprises in Kenya, mainly in the following aspects:

First, the recruitment of employees in some companies is not fully open to locals, and the absorption of local labor is limited, which limits the quantity and quality of jobs created by Chinese investment in Kenya. In most corporate reports, the number of Chinese employees exceeds the number of local employees. And, friction occurs when absorbing local labor. Kenya's "Labor Relations Law" stipulates those workers have the freedom to form and join trade unions, and they also have the right to organize collective strikes to increase wages and resolve disputes. What's more, Kenya's "Labor Organization Law" sets the minimum wage for workers. From 2015 to 2017, several Chinese-funded garment factories were troubled by workers' strikes to raise wages. In 2018, the Eldoret Highway Project, the capital of Wahinkisu County in western Kenya, undertaken by a Chinese-funded enterprise was met with demonstrations by some local road repair workers, demanding Chinese contractors to improve working conditions and wages, and claimed that if the problem is not resolved properly, work will not resume. In addition, there is a shortage of local high-quality skilled labor and manufacturing talents. Vocational education can play an irreplaceable role in reducing poverty and promoting economic development. However, many factors such as the shortage of education funds in Kenya, the severe lack of education facilities, the rapid population growth, and the backward social system have led to the low efficiency of vocational education.

Second, the cultural differences between China and Africa cause huge obstacles, including difficulties in corporate internal communication, goals of enterprises, cooperation methods, and operating methods. China and Africa differ greatly in economic systems, political systems, social values, and laws. Although both China and Africa have strong collectivism from cultural perspective. In a collective society, the interests of the group take precedence over the interests of the individual. People tend to see themselves as part of the group, and the members of a group take care of each other in exchange for loyalty. But in terms of power distance, China is centralized, while Africa is relatively decentralized. And the value of Africa in terms of masculinity is higher than that of China, which shows that Africa is medium masculinity, while China is medium femininity. In different cultures, people have different motivations for achievement. Masculinity values material wealth, money and self-confidence, while femininity culture values social relevance, quality of life and the welfare of others. This is manifested in Africans sometimes reluctant to cooperate, because their male culture generally regards cooperation as the sign of weakness, 
and attach great importance to independence and control. Moreover, the African people pay attention to short-term interests, while the Chinese people value long-term interests. Long-term interest-oriented cultures tend to save more money and show greater patience in waiting for results, while countries with short term interest-oriented cultures want to maximize current rewards and are relatively less inclined to long-term rewards.

Third, companies are not paying enough attention to environmental awareness. Kenya prohibits foreigners from carrying and using plastic bags when entering the country. The Kenyan government has repeatedly emphasized the "ban on plastics" on its official website and strictly restricts the recycling and reprocessing of plastics across the country. And Kenya has a special environmental court. The "Environmental Management and Coordination Law" established in 1999 introduced the principles of sustainable development, including public participation in environmental management (Han Xiuli,2020). Kenyans love the environment and have a high awareness of environmental protection, in that case, environmental risks are frequently encountered problems in the investment projects of Chinese-funded enterprises. The Nairobi-Malabar Standard Gauge Railway project undertaken by a Chinese company was to pass through the Nairobi National Park in Kenya and encountered environmental protests from local residents during its construction (Deng Zhicong,2020). The Kenya Environmental Court issued a suspension order. Although the Kenyan government supports the project and the route plan is also determined by the Kenyan government, the Chinese-funded company is only the contractor of the project, but the boycott and work stoppage suffered by the project have caused significant economic losses to the Chinese-funded company as well as Chinese investors, which also has a significant impact on the reputation of Chinese investors.

Fourth, business managers will make decisions based on their own values when avoiding uncertainty, which leads to higher potential transaction costs and internal management problems. Managers of Chinese and African companies also have different attitudes towards risk. Chinese managers with high uncertainty lack adventurous spirit and risk awareness (Daniel Fiott,2010). In other words, if they think that the situation is uncertain, they will avoid making decisions that would make them lose their opportunities in market competition. Most of the time, they want to ensure safety by taking less risky decisions. At the same time, the middle and lower-level supervisors are unwilling to make decisions without respecting their superiors. The result is that the time required for decisionmaking is much longer than expected and requires more input from participants at various social and professional levels. Therefore, the uncertainty avoidance measures developed in African countries indicate that low risk taking and resistance to changes may further delay the implementation of projects that encounter problems in the cycle.

\section{Measures to Solve the Problems of China's Enterprise Development in Kenya}

Kenya's oil and natural gas stocks are relatively low. Although some Chinese companies have provided exploration contracts, the Kenyan government has handed over bilateral natural resource exploration rights to the Chinese government and China National Offshore Oil Corporation. However, in terms of manufacturing activities, investment activities are mainly carried out by Chinese enterprises rather than the central government. These companies have been involved in many different areas in Kenya. The way Chinese companies develop in African countries is similar to the way they develop at home, mostly out of financial cautious considerations in order to improve efficiency, mainly by stimulating industries to carry out a certain degree of state intervention and economic benefits. Therefore, it is guided by national policies rather than liberalized development in the real economy. All in all, this also provides a valuable opportunity for African resource-rich countries to offset the "resource curse". Both Chinese companies and the Kenyan government must seize this precious opportunity to achieve a true win-win situation.

The first is to strengthen the proportion of local employees in the company. Enterprises provide local employees with educational materials and technical assistance in various fields to improve the employment skills of local young people, and promote the integration of industry and education to increase the absorption of local labor. What's more, enterprises open up some management positions to allow more local Kenyans to join the company's operation and management, thereby further improve the quantity and quality of local jobs created by Chinese investment in Kenya. For example, AVIC International Complete Set Company held the Africa Tech Challenge in Kenya, which helped trainees to improve their skills through practical training and competitions in lathe processing And the labor wage standards of enterprises should be formulated with reference to international labor standards. Chinese companies pay more attention to the individual talents of employees, and consider rewarding employees based on their performance, the principle of equal pay for equal work or based on their needs, so as to give full play to their talents and work performance to promote corporate development. What's more is to avoid corporate managers from adopting non-participatory decision-making methods and make decisions based on their own values, which will lead to higher potential transaction costs and internal management problems. The decision plan for major corporate issues should no longer be a simple transmission from the upper-level high-level to the lowerlevel high-level, but began to adopt participatory decision-making, that is, open a channel for soliciting opinions 
and collect the opinions of corporate personnel to allow staff in more positions and more classes can participate in decision-making, so as to concentrate the people's wisdom to make more scientific decision-making plans.

Second, Enterprise's environmental awareness needs to be enhanced. Faced with the introduction of the Kenyan government's environmental policies and the strong environmental awareness of Kenyans, companies must comply with Kenya's national environmental protection laws and regulations to make production decisions. With the development of economy, the environment on which mankind depends for survival is being severely damaged. Among them, global warming and air pollution problems are particularly prominent. At the same time, the environmental awareness of the international public is also changing. People tend to assess the health and environmental damage caused by pollution emissions with a higher monetary value, and more and more citizens are beginning to pay attention to the environmental performance of products and show environmental preferences when shopping. The awakening of international consumers' environmental awareness has also prompted companies to change their strategic thinking and be guided by market demand. Enterprises not only undertake the task of economic development, but also need to assume corresponding responsibilities in social responsibility, especially ecological social responsibility.

Finally, focus on eliminating the differences in Chinese corporate culture in Africa, creating an atmosphere of interdependence between the two peoples and a cohesive collective within the company, and enhancing the sense of belonging and dedication of local employees to the company. This also requires enterprise's managers and Chinese employees to first understand the African corporate culture, which also requires strengthening the knowledge popularization and exchange training of employees in terms of cultural differences. Even people with economic, political and cultural backgrounds have problems with effective communication, not to mention the difficulties and challenges faced by people from different countries and different cultural backgrounds when trying to communicate. Misunderstanding and lack of understanding are important aspects that hinder the development of multinational companies at the level of cultural differences. Therefore, Chinese companies in African countries should first understand the priorities and expectations of their business partners to more or less reduce misunderstandings. In the era of globalization, multinational companies will investigate various factors and subtle ways that affect business behavior and market behavior in advance, and cultural differences are the priority. That is to say, when companies formulate business strategies, cooperate and establish business partnerships, they need to break through conventional thinking to think.

\section{Conclusion}

The above mentioned the problems of low localization rate of corporate labor force, large cultural differences, weak corporate environmental awareness, and excessive risk aversion awareness in the development of Chinese enterprises in Kenya, and proposed targeted solutions. In addition, what needs to be added is that the overall education and health of the Kenyan country will also have a certain degree of influence on the in-depth development of Chinese enterprises in Kenya.

Kenya is a very young country. The median age is estimated to be 19 years, and approximately $80 \%$ of the Kenyan population is under 35 years of age. To a large extent, Kenya's youth defined as individuals between the ages of 18 and 35 will determine the future shape of the country. A survey which is conducted by the East Africa Institute of Aga Khan University in 2016 has interviewed 1,854 respondents between the ages of 18-35 in urban and rural areas of Kenya. According to the survey results, Kenyan youth value family, have faith and desire to work hard. They have the qualities that an entrepreneur should have: Most people want to start their own business, rather than a career in law, teaching, medicine, or engineering. Few youths want to become farmers. It can be indicated that the country's urbanization may continue to develop rapidly, thereby intensifying demand and competition for nonagricultural employment. In addition, most Kenyan youths are positive and optimistic about the future, and believe that the future will be more prosperous, provide more employment opportunities, and better access to health and education.

Specifically, young people have a positive attitude towards national politics and democratic leadership. For example, $90 \%$ of youths think voting is important, and $70 \%$ believe that they have the power to change the status quo. In the 21 st century, Kenya has seen an educational dividend: $78 \%$ of people have received primary education, and $39 \%$ of young people have received secondary education. Only $22 \%$ of people consider primary education as the highest level of education. These data also prove that the current youth are the best educated generation in Kenya so far. Regarding employment: Overall, the youth unemployment rate is $55 \%$. The female unemployment rate is the highest (62\%), and the rural female unemployment rate is even higher $(68 \%)$. The employment rate of people without higher education is the lowest (15\%). In contrast, $32 \%$ of highly educated people are unemployed. One out of every two graduates are unemployed, and only one-fifth of young people with a college degree are self- 
employed. Young people aged 18 to 25 suffer compared with unemployed people aged 26 to 35 .

However, $77 \%$ of young people believe that Kenya will become richer materially, have better access to quality education and health, and provide young people with more employment opportunities; $67 \%$ believe that society will reward merit and hard work. Therefore, the development of Chinese enterprises in Kenya and the growth of Kenyan youth in the highly competitive globalized world are mutually successful. Of course, Kenya's transition to a knowledge-based workforce cannot be separated from the foresight and responsiveness of the national vision development plan for youth development.

According to statistics from the World Health Organization, AIDS, tuberculosis, and malaria are more common in African countries. HIV-infected persons account for $70 \%$ of the global AIDS patients, malaria prevalence accounts for $90 \%$ of the global population, and tuberculosis patients account for one-third (World Health Organization,2019). Africa still has the largest number of people suffering from AIDS, of which sub-Saharan Africa has the largest number. About $10 \%$ of the population in countries such as Kenya, Uganda, Malawi, and Zimbabwe have been infected with the virus. In Kenya, being diagnosed with HIV is almost equivalent to being sentenced to death, because the management of life extension still requires a lot of resources, which most people cannot afford.

Undoubtedly, the severe test of the COVID-19 is for African countries with weak public health fields equals to add insult to injury. Most African countries have poor public health systems, poor public health conditions, backward medical equipment and technology, weak epidemic prevention and control capabilities. In that case, when they shift most of their energy to the prevention and control of the COVID-19, which means the prevention and control of multiple infectious diseases is superimposed, it will have an adverse impact on the allocation of medical and health resources for other diseases, such as shortage of medicines, reduction of relevant medical staff, and poor isolation measures. The lack of relevant medical services will lead to a sharp increase in the number of people infected with other diseases. The World Health Organization and the United Nations AIDS Research Group believe that when public health services for people living with HIV in African countries are concentrated on the new crown epidemic, their antiretroviral treatment will be interrupted, resulting in a dramatic increase in the number of AIDS-related diseases. Diseases, especially the COVID-19, are the common enemy of all mankind, shaping a tense global public health crisis and threatening the common interests of the people of the world. The national health of African countries also influences the level of development of Chinese enterprises in African countries to a certain extent.

The cooperation between China and Kenya is a sincere cooperation based on equality and mutual benefit, and is a model of South-South cooperation. Within the framework of China-Africa cooperation, the development of Chinese enterprises in Kenya has great potential, but it also faces many challenges, and to a certain extent, it will have an adverse impact on China-Africa cooperation in the future. This requires strengthening China-Africa bilateral understanding and continuing to play the role of the Kenya Employers' Federation. As the most representative employer organization in Kenya, it has a team of experienced experts and high social influence. Constantly improve the business environment in Kenya, safeguard the legitimate rights and interests of enterprises and entrepreneurs, serve member enterprises including Chinese-funded enterprises in Kenya, and promote harmonious labor relations among enterprises, which will also help Kenya realize its 2030 vision: to build a medium-developed industrialized country. Regardless of the breadth or depth of cooperation between China and Africa, there is still a lot of room for development.

The COVID-19 has severely impacted both China and Africa, and the field of health has become a new bright spot in China-Africa economic and trade cooperation(Zhong Shan ,2020).Under the existing framework of economic and trade cooperation between China and African countries, China is actively adding new cooperation projects on the public health industry, such as encouraging Chinese companies to start medical device manufacturing, medical drug manufacturing, hospital establishment, and public health service industry expansion in African countries. This new cooperation will inject vitality into the public health undertakings of African countries, and promote the long-term development of public health undertakings in African countries through market-oriented sustainable development. The further opening and expansion of the African market is a win-win result for both China and Africa, which can enable the full opening of both China and Africa to form multiple fulcrums in the international market. With Firmly believe in the prospects of mutual benefit and win-win cooperation between China and Africa, continue to reform and innovate China-Africa cooperation models. With the help of the "Belt and Road" initiative, China-Africa cooperation will continue to become a model of international cooperation, and this is what we should do to build a China-Africa Community with a Shared Future.

\section{References}

"World Malaria Report 2019: Summary", World Health Organization regional website. (December 4, 2019). 
Retrieved from https://www.who.int/malaria/media/world-malaria-report-2019/zh/

Barry, S., \& Yan, H. R. (2008). The Forest for the Tress: Trade, Investment and the China-in-Africa Discourse. Pacific Affairs, 81(1), 19-20. https://doi.org/10.5509/20088119

Chege, M. (2008). Economic Relations between Kenya and China, 1963-2007. In J. Cooke (Ed.), U.S. and Chinese Engagement in Africa: Prospects for Improving U.S.-China-Africa Cooperation (p. 30). Washington, D.C.: Center for Strategic and International Studies.

Daniel, F. (2010). The EU and China in Africa: The Case of Kenya. Madariaga Paper, 3(5).

Deng, Z. C. (2014). The labor dilemma of Chinese enterprises in Keny. WTO Economic Herald, (07), 80-81.

Han, X. L. (2020). The risk analysis of Chinese enterprises investing in Kenya. Overseas Investment and Export Credit, (01), 31-33.

Joyce, W. N., Esther, W., \& George, O. O. (2021). Effect of Market Culture and Hierarchy Culture on the Implementation of Corporate Strategy in Private Chartered Universities in Kenya. Journal of Business and Economic Development.

Kenya-China Economic and Trade Association. (2019). 2018-2019 Social Responsibility Report of Chinese Enterprises in Kenya. Retrieved from http://ke.mofcom.gov.cn/article/todayheader/201908/20190802895053.shtml

Liu, H. S., \& Niu, Z. Q. (2019). Effective collaboration to promote development-A delegation from the Chinese Enterprise Confederation visited the Kenya Employers' Federation and Tanzania Employers' Association. Enterprise Management, 27-28.

Opondo, M. (2019). The Impact of Chinese firms on CSR in Kenya's Garment Sector, BDS Working Paper, No. 7, (Mar., 2009) p.11.

Wang, H. Y. (2018). Innovative cooperation model to build a China-Africa community with a shared future. Global Times, 08-31(015).

$\mathrm{Xu}, \mathrm{H}$. (2019). China's image in Africa is generally positive and Chinese companies are widely recognized. China Report, (01), 38-41.

You, C. L. (2020). It is urgent for Chinese-funded enterprises in Kenya to establish an employee management system. Human Resources, (08), 104-105.

Zhong, S. (2020). Jointly Composing a New Chapter for the Forum on China-Africa Cooperation in the New Era. People's Daily, October 16, 10th edition.

\section{Copyrights}

Copyright for this article is retained by the author(s), with first publication rights granted to the journal.

This is an open-access article distributed under the terms and conditions of the Creative Commons Attribution license (http://creativecommons.org/licenses/by/4.0/). 